Jul 13th, 9:30 AM - 9:50 AM

\title{
Investing in Adaptation: Flood Risk and Real Option Application to Bilbao
}

\author{
Luis M. Abadie \\ Basque Centre for Climate Change (BC3), Im.abadie@bc3research.org \\ Elisa Sainz de Murieta \\ Basque Centre for Climate Change (BC3), elisa.sainzdemurieta@bc3research.org \\ Ibon Galarraga \\ Basque Centre for Climate Change (BC3), ibon.galarraga@bc3research.org
}

Follow this and additional works at: https://scholarsarchive.byu.edu/iemssconference

Part of the Civil Engineering Commons, Data Storage Systems Commons, Environmental Engineering Commons, Hydraulic Engineering Commons, and the Other Civil and Environmental Engineering Commons

Abadie, Luis M.; Sainz de Murieta, Elisa; and Galarraga, Ibon, "Investing in Adaptation: Flood Risk and Real Option Application to Bilbao" (2016). International Congress on Environmental Modelling and Software. 127.

https://scholarsarchive.byu.edu/iemssconference/2016/Stream-D/127

This Event is brought to you for free and open access by the Civil and Environmental Engineering at BYU ScholarsArchive. It has been accepted for inclusion in International Congress on Environmental Modelling and Software by an authorized administrator of BYU ScholarsArchive. For more information, please contact scholarsarchive@byu.edu, ellen_amatangelo@byu.edu. 


\title{
Investing in Adaptation: Flood Risk and Real Option Application to Bilbao
}

\author{
Luis M Abadie ${ }^{1}$, Elisa Sainz de Murieta ${ }^{1}$, Ibon Galarraga ${ }^{1}$ \\ 1 Basque Centre for Climate Change (BC3) \\ Edificio Sede Eraikina no.1, 1 / UPV/EHU Science Park \\ $B^{\circ}$ Sarriena s/n, / 48940 Leioa (Basque Country, Spain) \\ Email:Im.abadie@bc3research.org \\ Email 2: elisa.sainzdemurieta@bc3research.org \\ Email 3: ibon.galarraga@bc3research.org
}

\begin{abstract}
Investment decisions in adaptation are usually made under significant uncertainty due to climate change and socio-economic trends. Extreme events cause damage and may become more frequent over time. In this study we propose three ways to incorporate climate and socioeconomic uncertainty into the assessment of adaptation infrastructures in the city of Bilbao. The first suggestions is to use stochastic modelling, which makes it possible at any given time to estimate the present value of expected damage over a time period, considering that extreme events will increase in the future due to climate and socio-economic conditions. An analytical solution for the Net Present Value of investment at a given time is estimated here. Second, this is used to determine two risk measures: Value-at-Risk, which is widely used in financial economics, and Expected Shortfall, which is less common but a better risk indicator. We then define an additional stochastic model that contains four risk factors: the frequency of extreme events - modelled with three Poisson processes - and a stochastic growth rate of damage due to climate and socio-economic effects under uncertainty. Thirdly, we develop an example of Real Options Analysis (ROA), in which a binomial tree is used to study whether the best decision at present is to invest or to wait. The influence of several variables on the investment decision is analysed, including volatility, the discount rate and the expected growth rate of damage. This Real Option Analysis model calculates the boundary between the "investment region" and the "wait region" for different volatility levels and finds the optimum values for investment cost below which investment should take place. The model is illustrated with a case study concerned with the opening up of a canal in the city of Bilbao which will turn the Zorrotzaurre peninsula into an island and markedly decrease the potential for flood damage.
\end{abstract}

Keywords: Uncertainty; climate change adaptation; risk measure; stochastic modelling; flood-risk 